\section{European \\ Neurology}

Eur Neurol 2006;56:235

DOI: $10.1159 / 000096492$
Received: May 5, 2006

Accepted: July 17, 2006

Published online: October 20, 2006

\title{
Stroke MRI May Result in a Therapeutic Dilemma
}

\author{
L. Mechtouffa $\quad$ M. Hermier ${ }^{c} \quad$ B. Nader ${ }^{\text {a }} \quad$ S. Cartalat ${ }^{a} \quad$ L. Derex ${ }^{\text {a }} \quad$ S. Cakmak ${ }^{\text {a }} \quad$ J. Honnorat $^{\text {a }}$ \\ N. Nighoghossian ${ }^{b}$
}

${ }^{a}$ Cerebrovascular Unit and ${ }^{b}$ Department of Radiology, Hôpital Neurologique, Pierre Wertheimer, and

'CREATIS, UMR 5515, INSERM U 630, Lyon, France

Dear Sir,

A 68-year-old man with a past history of hypertension, diabetes mellitus and nonvalvular atrial fibrillation, developed an acute left ataxic hemiparesis and dysar-

thria. CT scan revealed a deep right capsular hemorrhage. Diffusion-weighted MRI showed a white matter area of recent ischemia (fig. 1a) and $\mathrm{T}_{2}{ }^{*}$-weighted gradient-
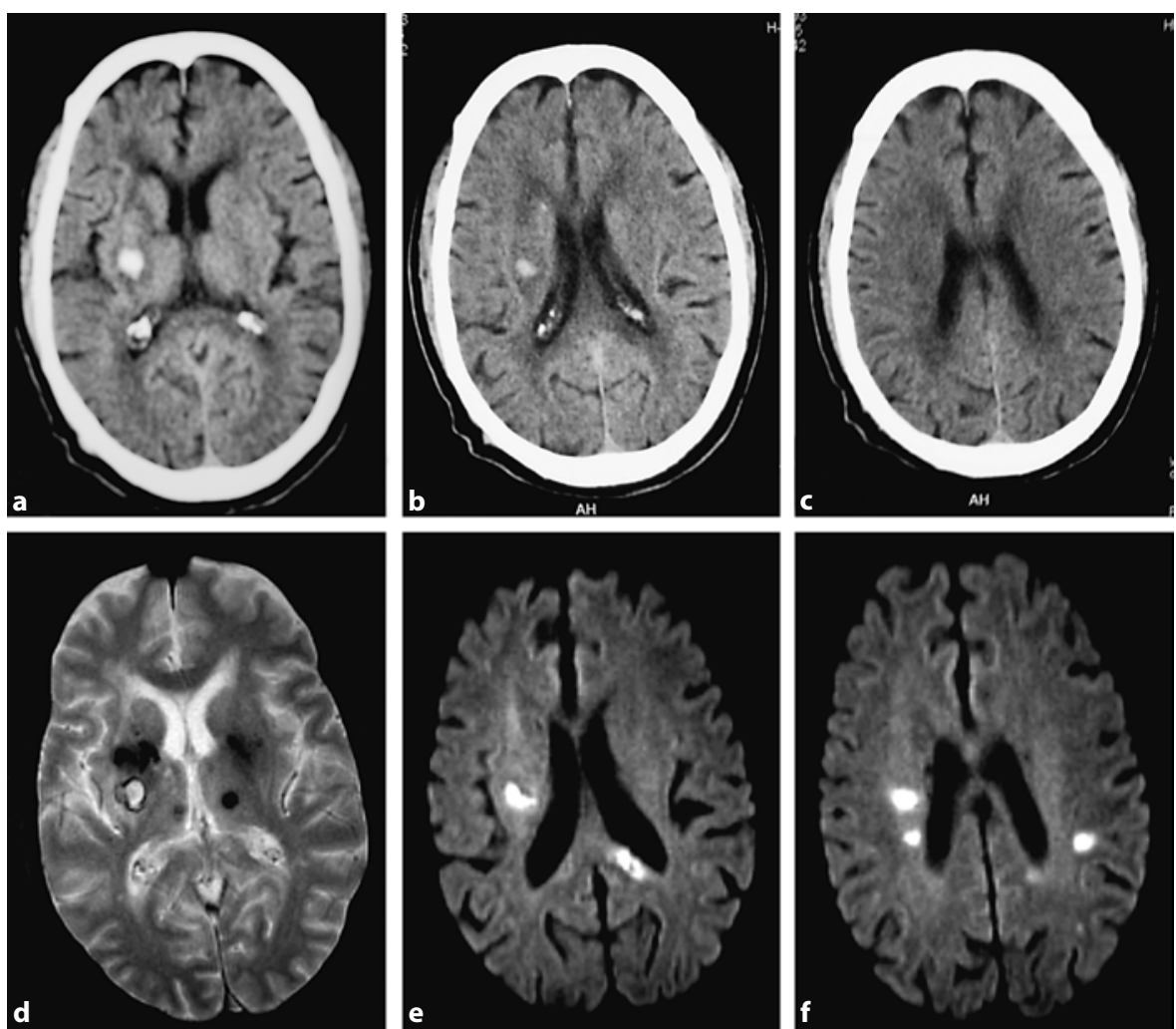

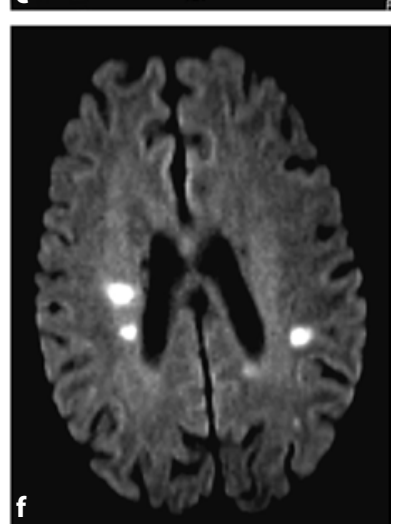

echo sequence disclosed old microbleeds (fig. 1b). The occurrence of acute primary hemorrhage and multiple ischemic damage may result in a therapeutic dilemma, although hemorrhagic transformation of a cardioembolic stroke cannot be excluded in this patient.

Anticoagulation is usually recommended in secondary prevention of ischemic stroke in atrial fibrillation. The use of low-molecular-weight heparin (LMWH) in patients with nonvalvular atrial fibrillation at the acute stage is well documented [1].

Moreover, the administration of LMWH in patients with intracerebral hemorrhage is actually recommended [2] for the prevention of deep vein thrombosis in patients with intracerebral hemorrhage.

The use of LMWH might prevent both early ischemic recurrence in atrial fibrillation [1] and deep vein thrombosis [2] in patients with intracerebral hemorrhage.

\section{References}

1 Berge E, Abdelnoor M, Nakstad PH, Sandset PM, on behalf of the HAEST Study Group: Low molecular-weight heparin versus aspirin in patients with acute ischaemic stroke and atrial fibrillation: a double-blind randomised study. Lancet 2000;355:1205-1210.

2 Priorities for Clinical Research in Intracerebral Hemorrhage: Report from a National Institute of Neurological Disorders and Stroke Workshop. Stroke 2005;36:e23-e41.

Fig. 1. a-c CT scan showing a right capsulo-lenticular haematoma. d Rim of signal loss consistent with recent haemorrhage. Multiple microbleeds on T2*-weighted image. e, f Multiple hypersignal on diffusion-weighted MRI.

\section{KARGER}

Fax +41613061234 E-Mail karger@karger.ch www.karger.com
(C) 2006 S. Karger AG, Base

0014-312X/06/0564-0235\$23.50/0

Accessible online at:

www.karger.com/ene
Prof. Norbert Nighoghossian

Hôpital Neurologique, Pierre Wertheimer

59 Bd Pinel

FR-69003 Lyon (France)

Tel. +33 472357 810, Fax +33 472357 806, E-Mail norbert.nighoghossian@chu-lyon.fr 